\title{
O existencialismo em Sartre: subjetividade e sociedade do conhecimento
}

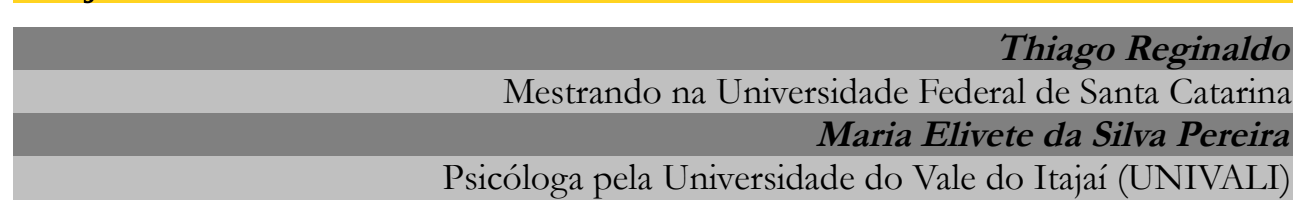

\section{Resumo}

Este artigo relaciona a teoria existencialista de Sartre com os aspectos atuais da sociedade do conhecimento atrelados à educação. Para tanto o ser é tomado a partir da sua (inter) subjetividade que se estabelece na relação consigo mesmo, com o outro e com o mundo. A partir da trama dessas relações o conhecimento disseminado passa a ser filtrado e orientado entre os sujeitos. Para que haja um resgate à subjetividade, autonomia da consciência humana assentada no desenvolvimento das capacidades cognitivas e afetivas de problematização e apreensão da realidade, no entanto, necessitará de uma formação global com participação crítica baseada na ação e compreensão no mundo.

Palavras chave: Existencialismo; Subjetividade; Sociedade do Conhecimento.

\begin{abstract}
This article relates Sartre's existentialist theory with current aspects of knowledge society linked to education. Therefore being is taken from a view of their (inter) subjectivity that establishes the relationship with oneself, with others and with the world. From the plot of these relations widespread knowledge becomes filtered and walked among the subjects. For there to be a ransom to subjectivity, autonomy of the seated human consciousness in the development of cognitive and affective capacities of questioning and apprehension of reality, however, need the global formation with critical participation based on action and understanding in the world.
\end{abstract}

Keywords: Existentialism; Subjectivity; Knowledge Society.

Filosofia e Educação [rfe] - volume 7, número 1 - Campinas, SP

Fevereiro-Maio de 2015 - ISSN 1984-9605 - p. 109-126 


\section{Introdução}

Ddas as sociedades ao longo da história da humanidade podem ser chamadas de sociedades do conhecimento, uma vez que produziram informações, cultura e outros ativos tangíveis e intangíveis que colaboraram para sua formação e seu desenvolvimento. No entanto, o que alcunha este termo na sociedade atual está ligado aos processos midiáticos e de relações sociais em que informações e conhecimentos no campo da ciência e produção humana aparecem em alta escala e surge, então, a necessidade de filtros para gerir tamanha demanda informacional. Liga-se a isso de modo direto o processo de globalização da economia que contribui para a formação de uma sociedade cada vez mais complexa e especialista.

$\mathrm{Na}$ formação dessa sociedade complexa e multicultural que está gradativamente mais ao alcance de todos pelas redes de comunicação existem vários aspectos que influenciam em como o indivíduo compreende sua existência, seu ser no mundo e no modo como se relaciona com as pessoas neste mundo. A educação pode aparecer nessa esfera como oportunidade de reflexão, mediação de processos, de atitudes ativas e compartilhadas. A partir disso então é possível construir uma nova forma de interpretar as informações midiáticas e compreender seus conhecimentos disseminados. Contudo, apesar das mudanças na sociedade em todos esses anos e das novas relações com o mundo a constituição do indivíduo continua a se estabelecer pelo dialogismo sujeito-mundo. Compreender tal realidade transfigura em entender a partir da visão existencialista como o indivíduo se posiciona no mundo e toma suas atitudes. A partir disso surge a definição de subjetividade com dois significados: (1) "a escolha do sujeito individual por si próprio e, por outro lado, impossibilidade em que o homem se encontra de transpor os limites da subjetividade humana", e (2) 
“constituir o sentido profundo do existencialismo", ambos de Sartre (1987, p. 6). Pelo segundo significado pode-se compreender que a subjetividade aparece através da existência e da experiência ser no mundo. A consciência permite que a subjetividade atinja seu plano de expressão.

Visto isso o presente artigo prossegue com o objetivo de traçar possíveis relações entre a teoria existencialista em Sartre sobre a (inter) subjetividade do sujeito e o atual contexto da sociedade do conhecimento. $\mathrm{O}$ texto segue uma linha de pensamento que se estrutura em torno do existencialismo com uma discussão que começa pela consciência, sujeito e sua subjetividade nas relações consigo mesmo, com o outro e com o mundo; em reflexões sobre o comportamento do ser e do sujeito no contexto do conhecimento; e por fim apresenta uma discussão sobre a educação na sociedade do conhecimento.

\section{Sartre, o existencialismo e o sujeito}

Jean-Paul Sartre, filósofo e escritor francês, deixou importantes contribuições filosóficas, bem como ampliou o leque das abordagens psicológicas com sua teoria marcada pelo existencialismo. Através dessa teoria o filósofo aborda a consciência como uma forma de fazer com que o ser se liberte em analogia a um sujeito emancipado e responsável pelas suas escolhas. Aqui o sujeito se faz na relação com o mundo, ou seja, indivíduo e mundo se constituem mutuamente num processo constante de vir a ser. O autor contrapõe outras vertentes da psicologia quando afirma que primeiro o sujeito existe para então ser essência", ou seja, a "existência precede a essência".

\footnotetext{
${ }^{1}$ A essência envolve as características da subjetividade humana e só pode ser considerada a partir da existência, já que, o homem não é nada antes de se fazer algo e que a finalidade de ação do homem é se autodefinir. Isso configura liberdade à existência humana.
}

Filosofia e Educação [rfe] - volume 7, número 1-Campinas, SP

Fevereiro-Maio de 2015 - ISSN 1984-9605 - p. 109-126 
Mas se realmente a existência precede a essência o homem é responsável pelo que é. Assim, a primeira decorrência do existencialismo é colocar todo o homem em posse daquilo que ele é, e fazer repousar sobre ele a responsabilidade total por sua existência. E quando dizemos que o homem é responsável por si mesmo, não queremos dizer que ele é responsável estritamente por sua individualidade, mas que é responsável por todos os homens. (SARTE, 2013, p. 26)

A ideia da responsabilidade coletiva remete a uma sociedade em que cada sujeito exerce influências um com o outro, o que evidencia um padrão de rede social mesmo antes do advento da cultura digital que potencializa isso. Para este filósofo o mundo pode ser descrito como objetivo e o sujeito subjetivo. Homem e mundo aparecem aí como tarefas inacabadas, visto que nessas redes de relações se processam as transformações que passam a representar outra vez novos elos, que se entrelaçam formando novas correntes que serão significadas e ressignificadas num movimento contínuo e constante. Dessa forma o sujeito é marcado pelo mundo e vice-versa. O pensamento sartriano afirma que "o homem é um ser em constantes buscas. Somos aquilo que buscamos, somos um pouco de muitos. Somos um eu na multidão que se auto-cria e que também se autodestrói” (SOUZA, 1987, p. 29).

Ao se pensar no sujeito como objeto de análise na teoria existencialista torna-se necessário rastrear a sua história para verificar onde foi que se apreendeu, ou foi aprisionado, em que parte da sua estória está o nó, ou seja, que significados que recebeu do mundo e de que forma vivenciou estes significados. Assim quando, pretende-se conhecer um homem, necessariamente deve-se começar conhecendo a sua história, objetivá-lo, ou seja, localizá-lo no tempo e no espaço. Conhecer o espaço 
onde este homem vive. Deste modo reitera Sartre (2013, p.81): "nunca discutimos o fato de que o homem, constantemente, é um objeto para o homem, mas reciprocamente, para se apreender o objeto enquanto tal, é preciso haver um sujeito que se apresente como sujeito".

Do mesmo modo, não seria diferente o movimento na busca do conhecimento sobre algum lugar (mundo). Deve-se partir em direção aos sujeitos, observar atentamente seus hábitos, seus costumes, enfim, procurar conhecer as características dos indivíduos que habitam este lugar. Para Sartre o sujeito é a sua história e esta se faz dentro do mundo, dentro de uma época. É fundamental, conhecer este sujeito através do tempo presente e voltar no caminho (passado). Para ele "cada época se desenvolve seguindo leis dialéticas e os homens dependem da época e não de uma natureza humana" (SARTRE, 2013, p. 81).

Em um processo terapêutico, por exemplo, devem-se recolher os dados, separar, selecionar expor estes conteúdos à luz da consciência na compreensão do sujeito e posteriormente analisar, refletir a cerca desses fatos e ressignificá-los de modo que a pessoa em conflito possa tomar as mãos sua história e modificá-la pelas suas novas escolhas, pautadas por uma nova consciência e trazê-la para a realidade através da ação. Então desta maneira o ser pode se fazer presente através de um novo projeto, pois "o homem nada mais é do que seu projeto, ele não existe senão na medida em que se realiza e, portanto, não é outra coisa senão o conjunto de seus atos, nada mais além de sua vida" (SARTRE, 2013, p. 42). O projeto pode ser compreendido neste ponto de vista como a própria vida que engloba o ser (aparecer) no mundo, a construção do sujeito e os laços estabelecidos com os outros.

É prudente ao sujeito que pela compreensão do pensamento existencialista traga a sua consciência que o mundo que o cerca ao mesmo

Filosofia e Educação [rfe] - volume 7, número 1 - Campinas, SP Fevereiro-Maio de 2015 - ISSN 1984-9605 - p. 109-126 
tempo em que acolhe o repele, conforta e o desconforta, ajusta e o desajusta, liberta e o aprisiona. Perante isso o sentimento se constrói na ação a todo instante, então, o agir de modo responsável se faz fundamental já que as ações não repercutem apenas no próprio sujeito, mas em toda a humanidade. Neste excerto é possível verificar isso:

Tudo acontece para cada homem como se a humanidade inteira estivesse sempre com olhos sobre o que ele faz para agir de maneira semelhante. E cada um deve se perguntar: Sou eu mesmo o homem que tem o direito de agir de forma tal que a humanidade se orienta por meus atos? (SARTRE, 2013, p. 30).

Nota-se pelas observações feitas até então que o existencialismo traz consigo a angústia, e caso isso não aconteça, ela estará mascarada. Esta angústia, apresentada aqui, está livre de levar a inação, mas pela ação, uma angústia que traz a responsabilidade. Ao mesmo tempo em que é livre, o homem encontra-se condenado a inventar-se a cada instante, sem nenhum tipo de apoio a priori, se não por ele mesmo, e este desamparo é acompanhado de angústia. Para Sartre (2013, p.31), “essa espécie de angústia, que é a que descreve o existencialismo, veremos que ela se explica, além disso, por uma responsabilidade direta em relação aos homens envolvidos pela escolha".

O processo de escolha só é possível na medida em que o sujeito se distancia do objeto (mundo) de forma crítica e reflexiva e se apropria apenas daquilo que lhe serve, através de escolhas responsáveis, sendo aí que se encontra a sua liberdade. Dessa maneira "a escolha é possível em um sentido, mas o que não é possível é não escolher. Eu sempre posso escolher, mas tenho que saber que se não escolho, isto também é uma escolha" (SARTRE, 2013, p. 51). Tais processos de escolha irão influenciar na 
construção da personalidade desse sujeito e consequentemente na sua subjetividade.

\section{O ser e a subjetividade para Sartre}

Para Sartre o sujeito está na ordem dialética entre intersubjetividade (exterior) e subjetividade (interior), segundo as quais se torna aquilo que é visto e, ao mesmo tempo, afasta-se de uma identificação absoluta consigo mesmo (PEREIRA, 2008). Assim, se estabelece também a relação com sua consciência que não existe sem o mundo, nem mundo sem consciência. Consciência é intencionalidade e a subjetividade se constitui frente a algo revelado pela existência através da essência.
A consciência é revelação-revelada dos existentes, e estes comparecem a elas fundamentados pelo ser que lhes é próprio. Mas a característica do ser de um existente é não se revelar a si, em pessoa, à consciência: não se pode despojar um existente de seu ser; o ser é o fundamento sempre presente do existente, está nele e em toda parte e em parte alguma; não existe ser que não seja ser de alguma maneira ou captado através dessa maneira de ser que o manifesta e encobre ao mesmo tempo. (SARTRE, 1997, p. 35).

Como verdade absoluta da consciência que apreende a si mesma Sartre (1987) cita o argumento do cogito utilizado por Descartes, que afirma: penso, logo existo. Dessa forma, fora do cogito todos os objetos são apenas prováveis e para definir o provável há de se possuir o verdadeiro (SARTRE, 1987). A verdade está ao alcance de todo mundo: "consiste no fato de eu me apreender a mim mesmo, sem intermediário" (SARTRE, 1987, p. 15). No entanto, Sartre (1987) afirma que no cogito não se descobre apenas a si mesmo, mas também aos outros. 
Nesse sentido, ao se pensar na subjetividade do ser é preciso compreendê-la no sujeito que é um ser consciente para-si, uma vez que, o eu está presente na consciência para a própria pessoa que se vê no que faz. Para se delinear melhor esta explicação de subjetividade a partir da consciência é preciso partir para outros conceitos que também giram em torno do ser e que tem ligação com a formação do ser e sua presença no mundo.

Na obra O Ser e o Nada (SARTRE, 1997) o filósofo revela aspectos do ser que chama de o ser em-si, para-si e para-outro. O ser em-si é o que é - o ser da consciência, não mantém relação com o outro, não se coloca como o outro a não ser a si mesmo. Um ser em-si não tem potencialidades nem consciência de si ou do mundo. Apresenta-se como um ser manifestante que não estabelece relações com outros seres e é independente de qualquer coisa, representa a materialidade. O para-si é o contrário do ser em-si, pois ele busca a si mesmo, representa a consciência. No entanto, o si que a consciência busca está fora dela mesma no mundo. Aí surge a transcendência do si mesmo na busca do que falta para se fundamentar. O desejo do para-si está no ato de apropriação de si mesmo nessa busca com o exterior. Desta forma o sujeito está em constante transformação a partir de suas escolhas. Já o ser para o outro é o ser diante do outro. A presença do outro é minha consciência, me vejo através do olhar do outro. O outro é o mediador entre eu e eu mesmo. Se o ser é para o outro, reconhece-se pelo outro, ou seja, como o outro o vê.

[...] o outro não apenas revela-me o que sou: Constitui-me em novo tipo de ser que deve sustentar significações novas. Este ser não estava em mim em potência antes da aparição do outro, pois não teria encontrado lugar no Para-si, e mesmo se algo se satisfizesse em me dotar de um corpo inteiramente constituído antes que esse corpo fosse para os outros [...], pois estas são significações e, como 
tais, transcendem o corpo e remetem ao mesmo tempo a uma testemunha capaz de compreendê-las e à totalidade de minha realidade humana. Mas este novo ser que aparece para o outro não reside no outro: eu sou responsável por ele. (SARTRE, 1997, p. 290)

Não obstante, a visão do outro sobre o ser é a visão que outro consegue manifestar a partir de suas construções e não pode ser definida como verdadeira. Compõe-se deste modo um assunto complexo a compreensão e delimitação do ser para-si. Nesta relação do outro e do mundo, todavia, a subjetividade tem um espaço para aparecer. A subjetividade para Sartre (2013) não se releva apenas a si, mas tem relação direta com os outros, ela é o que ele chama de intersubjetividade - o sujeito apreende diante do outro e o outro é tão necessário para o sujeito como ele próprio. O outro é condição para a sua existência. Existir é estar presente e este estar presente significa o ser que é presente e o ser pelo qual o ser se faz presente.

Para obter qualquer conceito sobre mim, é necessário que eu passe pelo outro. O outro é indispensável para minha existência, tanto quanto, ademais, o é para meu autoconhecimento. Nessas condições, a descoberta de meu íntimo revela-me, ao mesmo tempo, o outro como liberdade colocada diante de mim, que sempre pensa e que a favor ou contra mim. Assim descobrimos imediatamente um mundo que chamaremos de intersubjetividade, um mundo em que o homem decide o que ele é e o que os outros são. (SARTRE, 2013, p. 48)

Continuando a pensar na subjetividade do sujeito, Sartre afirma que Filosofia e Educação [rfe] - volume 7, número 1 - Campinas, SP Fevereiro-Maio de 2015 - ISSN 1984-9605 - p. 109-126 
existe uma universalidade humana de condição, um limite que traça sua situação fundamental no universo, porém é impossível encontrar em cada homem uma essência universal. Isso acontece, visto que, cada sujeito apresenta uma realidade social e historicamente construída ao longo dos tempos. O que não varia é a necessidade do homem estar no mundo, conviver com os outros.

Tais limites não são nem objetivos nem subjetivos, ou quem sabe eles tenham um lado objetivo e outro subjetivo. São objetivos porque se encontram em toda a parte e são em toda parte reconhecíveis; e são subjetivos porque são vividos e não são nada se o homem não os vive, ou seja, se não se determina livremente em sua existência em relação a eles. E embora os projetos possam ser diferentes, ao menos nenhum deles me é completamente estranho, porque todos eles são uma tentativa de superar esses limites ou afastá-los ou negá-los ou acomodar-se a eles. Consequentemente, todo projeto, mesmo que seja individual, possui um valor universal. (SARTRE, 2013 p. 48-49).

Assim podemos dizer que existe uma universalidade, porém ela é construída permanentemente - "edifico esta universalidade ao escolher-me". (SARTRE, 2013, p. 49). O interessante é perceber a relação social e histórica que Sartre estabelece na relação entre objetividade e subjetividade na formação do sujeito. O ser passa por um processo de construção do seu ser a partir das relações que estabelece com o mundo e se descobre a partir da interação com o mundo.

\section{Reflexões sobre educação na sociedade do conhecimento}

Nos últimos anos, à medida que a sociedade se transformou e caminhou

Filosofia e Educação [rfe] - volume 7, número 1 - Campinas, SP

Fevereiro-Maio de 2015 - ISSN 1984-9605 - p. 109-126 
rumo à era informacional ou do conhecimento diferentes tecnologias e modelos digitais foram criados e tem impacto direto na educação. De acordo com Tedesco (2009) no mundo aonde se acumulam e circulam informações e conhecimentos através de tecnologias gradativamente mais poderosas o papel dos espaços educativos deve ser definido pela sua capacidade para preparar o uso consciente, crítico e ativo de tais dispositivos.

Com esses aparatos tecnológicos o indivíduo passou e passa a observar o mundo a partir de diferentes lentes. Essa relação atual do sujeito com o mundo e do mundo com o sujeito acontece através da virtualidade por meio de processos de comunicação que trazem novas perspectivas dentro do pensamento apresentado por Sartre. Esses aspectos podem entrar como a condição universal do sujeito devido à época em que se vive hoje, onde o indivíduo já nasce na era digital. Deste modo, a sociedade digital e em rede passa a fazer parte da constituição do sujeito.

Com a sociedade conectada e com padrões complexos de desenvolvimento, se torna uma tarefa árdua estabelecer reflexões sociais nos sujeitos e emancipar suas atitudes devido às formas de globalização das informações. A educação emancipadora e o conhecimento podem se tornar formas de levar o sujeito a superar seus limites através da consciência. A consciência está no fato de olhar para o que está acontecendo no mundo e poder se posicionar perante isso.

A relação do sujeito com os meios de comunicação midiáticos pode acontecer de diferentes formas a partir da simples introjeção ou reflexãocrítica dos conteúdos que lhe são apresentados. É preciso apontar que o sujeito é livre para fazer suas escolhas, pois, até mesmo o não escolher é uma escolha. Por exemplo, os noticiários têm anunciado muitas tragédias, guerras e outras notícias envolvendo atos de violência, enquanto uns procuram soluções com iniciativas sociais ou educativas outros apenas

Filosofia e Educação [rfe] - volume 7, número 1 - Campinas, SP Fevereiro-Maio de 2015 - ISSN 1984-9605 - p. 109-126 
assistem passivamente o que está acontecendo e esta inércia colabora para a manutenção do desastre. Assim, para que se tenha uma atitude reflexiva e crítica perante os meios de comunicação e como resultado uma postura emancipatória é preciso de responsabilidade nas suas escolhas e compreensão da realidade em que se está inserido. Para favorecer este processo de escolha a educação para os meios deve capacitar à participação crítica $^{2}$ afirma Buckingham (2012, p. 53):

Precisamos capacitar os jovens a se tornarem participantes ativos na cultura de mídia; porém, não basta apenas participação ou criatividade por si próprias. É preciso, também, que sejam participantes críticos, desenvolvendo um entendimento mais amplo das dimensões econômicas, sociais e culturais da mídia entendimento este que não resulta automaticamente da produção criativa.

A liberdade da escolha perante uma participação crítica possibilita ao o sujeito a reflexão e análise na definição de projetos e ser no mundo. Perante isso o ser no mundo do sujeito passa a ter filtros para conseguir selecionar e ser consciente. Os filtros poderiam ser descritos como uma forma de manter o sujeito atento ou alheio perante a consciência. $\mathrm{O}$ uso desses filtros irá causar um mal estar, o que Sartre chama de náusea ou angústia, caso contrário, será incorporado as suas atitudes o sentimento de "estar na multidão", ou seja, ser mais um sujeito no mundo capital. Assim, para a transformação do sujeito e do mundo é preciso dessa inquietação angustiante. Trata-se de um processo de construção e desconstrução que leva a reflexão e crítica dos objetos, pessoas e mundo. Para refletir sobre

${ }^{2}$ Crítica no sentido de engajar-se em análises profundas do sistema, de se afastar da experiência imediata para poder refletir e analisar (cf. BUCKINGHAM, 2012).

Filosofia e Educação [rfe] - volume 7, número 1 - Campinas, SP

Fevereiro-Maio de 2015 - ISSN 1984-9605 - p. 109-126 
isso é preciso se distanciar, estar fora, para poder se posicionar frente aquilo e poder ter um olhar consciente. Para ter novas atitudes perante algo é preciso compreendê-lo, olhar em todas as faces do fenômeno, e o conhecimento permite que isso aconteça. Uma vez distanciado do contexto aparece à possibilidade de transformar-se e transformar.

A compreensão da construção de conhecimento e dos processos midiáticos frente a essa realidade apresentada corrobora para a formação emancipatória de sujeitos desde a mais tenra idade até os mais velhos. O conhecimento se configura para Sartre como algo absoluto numa tentativa de representação de ser o que não se é:

Quero captar este ser e não encontro senão eu mesmo. O conhecimento, intermediário entre o ser e o não-ser, remete-me ao ser absoluto se pretendo fazê-lo subjetivo e a mim mesmo quando suponho captar o absoluto. O sentido mesmo do conhecimento é ser o que não é e não ser o que é, porque, para conhecer o ser tal como é, seria necessário ser este ser; mas não há esse "tal como é" salvo porque não sou o ser que conheço, e, se me convertesse nele, o "tal como é" desvanecer-se-ia e já nem sequer poderia ser pensado. (SARTRE, 1997, p. 286)

Essa definição de conhecimento compreende que a realidade das mídias e dos processos de comunicação em rede é formada por pessoas e suas relações se estabelecem através das pessoas, ou seja, é algo humano com interfaces tecnológicas. Para a melhor compreensão e estruturação desse conhecimento nas mídias por essa visão precisa-se entender o que Sartre chama para-outro. É pelo para-outro que existe a possibilidade de mediar um processo e despertar o conhecimento: "é somente na medida em que se opõe ao outro que cada um é absolutamente Para-si; afirma contra o 
outro e frente ao outro seu direito de ser individualidade" (SARTRE, 1997, p. 307). Dessa forma, o ser humano apreende a realidade através de uma rede de colaboração na qual cada ser ajuda o outro a desenvolver-se, ao mesmo tempo em que também se desenvolve. Todos aprendem juntos e em colaboração. Como afirma Freire ${ }^{3}$ (1993, p.9), "ninguém educa ninguém, como tampouco ninguém educa a si mesmo: os homens se educam em comunhão, mediatizados pelo mundo".

Ao se pensar os sistemas educacionais formais o educador tem a função de facilitar a criação de sentido e significado à interlocução entre o estudante e as plataformas digitais e midiáticas. Para Freire (1983, p.47), "a educação é comunicação, é diálogo, na medida em que não é transferência de saber, mas um encontro de sujeitos interlocutores que buscam a significação dos significados", e por isso destaca-se aqui a importância da concepção dialógica da comunicação na educação. Nessa disseminação do conhecimento pela comunicação um novo horizonte pode ser alcançado através da mediação do educador-estudante e como resultado um ser mais crítico no mundo perante a grande quantidade de informações da mídia em massa. O educador como resultado contribuirá para a formação da individualidade do estudante. Isso pode ser feito através da mediação educador/estudante/comunidade em orientações de processos educativos e de conhecimento. Deve-se despertar a reflexão no estudante por estes processos, o despertar de uma participação crítica do sujeito no mundo com resultado em ações.

A ação esperada diante da reflexão no estudante se enquadra no existencialismo de Sartre (1987) que afirma que a vida humana é possível e que toda a verdade e ação implicam na subjetividade humana. Isso ancora o projeto humano de cada um que é subjetivo e individual, porém, universal já

3 A pedagogia libertadora de Freire encontra inspiração filosófica na fenomenologia existencial (cf. SAVIANI, 2005).

Filosofia e Educação [rfe] - volume 7, número 1 - Campinas, SP

Fevereiro-Maio de 2015 - ISSN 1984-9605 - p. 109-126 
que orienta a humanidade a seguir seus atos. Deste modo, Freire (1983) afirma não há possibilidade de dicotomia do homem e do mundo, visto que não existe um sem o outro. $\mathrm{O}$ autor constata que pela ação do homem no mundo, através de sua ação sobre ele, o homem encontra as marcas de sua própria ação. Além disso, "não podemos nos assumir como sujeitos da procura, da decisão, da ruptura, da opção, como sujeitos históricos, transformadores, a não ser assumindo-nos como sujeitos éticos" ${ }^{\prime 4}$ (FREIRE, 2005, p. 17).

Como observado até aqui, a teoria de Sartre pode ser pensada em conjunto com a Pedagogia Libertadora de Freire que se enquadra na corrente pedagógica sociocrítica de Libâneo (2005). Entretanto, com as novas representações sociais e a complexidade da sociedade do conhecimento outras correntes além dessa precisam ser referidas aqui para uma compreensão ampla de outros termos que também contribuem para a compreensão da emancipação do sujeito e sua subjetividade, entre elas, as holísticas e pós-modernas. De acordo com Libâneo (2005) as correntes holísticas enxergam a realidade como integração entre o todo e as partes, sua complexidade e natureza; e as correntes pós-modernas valorizam os muitos discursos, linguagens e diferenças para o desenvolvimento da consciência. Esses conceitos apresentados indicam que a subjetividade e os conhecimentos do mundo se apresentam de diferentes formas e implicarão, quando respeitados e compreendidos, em sujeitos mais plurais e respeitosos. O autor alerta, todavia, que é preciso ter cuidado para que na sociedade do conhecimento, a despeito de todas essas teorias, não haja somente um saber fazer, mas uma preocupação com a formação geral:

${ }^{4} \mathrm{O}$ ético para Freire está ligado a algo indispensável à convivência humana, constituinte do sujeito e em conformidade com sua liberdade.

Filosofia e Educação [rfe] - volume 7, número 1 - Campinas, SP

Fevereiro-Maio de 2015 - ISSN 1984-9605 - p. 109-126 
Não há uma crise de formação; há um contexto concreto de transformações sociais, econômicas, políticas que tendem a privar a humanidade e, portanto, os processos formativos, de perspectivas de existência individual e social. A formação global do ser humano, portanto, continua sendo condição de humanização e tarefa da pedagogia, onde se inclui certamente o desenvolvimento da razão. Mas trata-se de uma racionalidade que resgata a subjetividade, a autonomia da consciência humana, assentada no desenvolvimento das capacidades cognitivas e afetivas de problematização e apreensão da realidade. (LIBÂNEO, 2005, p.41)

Desse modo a formação global tem relação com o ser no mundo de Sartre em todas suas potencialidades de subjetividade, individualidade, direito a diferenciação, aprendizado, afetividade, compartilhamento e relações sociais. Isso contribui para um cidadão consciente e ético que caminha rumo a sua liberdade. Não se deve esquecer, no entanto, da relação do ser no mundo e da sua universalização e ação coletiva - à medida que o ser se constrói ele influi para além de si no outro e no mundo. Dessa maneira na sociedade do conhecimento as formas de comunicação e compreensão do mundo podem ser utilizadas de maneira reflexiva e comprometidas em processos mediados e emancipatórios.

\section{Considerações finais}

Este artigo traçou algumas das possíveis relações entre a teoria existencialista de Sartre sobre a (inter) subjetividade do sujeito no atual contexto da sociedade do conhecimento. Percebe-se que além das características subjetivas do sujeito a teoria existencialista de Sartre constata a intersujetividade através da relação do para-outro como uma forma de estabelecer a subjetividade e o ser para-si. Ao se relacionar a (inter) 
subjetividade aos processos atuais da sociedade pode-se pensar que o conhecimento disseminado necessita ser filtrado e orientado entre os sujeitos. Para tanto, de modo que haja uma participação crítica, as atividades educativas precisam ser emancipatórias e contribuírem para um eu ético. Além disso, deve-se estar atento a uma formação global, que não está relacionada somente ao saber fazer, mas ao resgate da subjetividade e autonomia da consciência humana.

À medida que os processos de conhecimento e compreensão da mídia se revelam na consciência estruturado nas relações humanas o ser se constitui e constitui o mundo. Para tanto, o ser no mundo e o sujeito precisam ter uma estrutura de ação de construção e desconstrução de si. Para tanto, a inquietação angustiante e o distanciamento são formas de se posicionar e fazer escolhas neste mundo.

\section{Referências}

BUCKINGHAM, David. Precisamos realmente de educação para os meios? Comunicação \& Educação. Ano XVII, n. 2, jul/dez 2012, p.41-60.

FREIRE, Paulo. Extensão on Comunicaşão. 8. ed. Rio de janeiro: Paz e Terra, 1983.

. Pedagogia da Autonomia. 31. ed. São Paulo: Paz e Terra, 2005.

. Política e educação. São Paulo: Cortez, 1993.

LIBÂNEO, José Carlos. As teorias pedagógicas modernas revisitadas pelo debate contemporâneo na Educação. In: LIBÂNEO, J. C.; SANTOS, A. (Orgs.). Educação na era do conbecimento em rede e transdisciplinaridade. Campinas: Alínea, 2005, p. 15-58. Disponível em: <http://www.ia.ufrrj.br/ppgea/ conteudo/T1SF/Akiko/03.pdf>. Acesso em: 13 jul. 2014.

PEREIRA, Deise Q. Sartre fenomenólogo. Estudos e pesquisas em psicologia, UERJ, Rio de Janeiro, ano 8, n. 2, 2008, p. 277-288. 
SARTRE, Jean-Paul. O existencialismo é um humanismo. 3. ed. São Paulo: Nova Cultural, 1987. O existencialismo é um humanismo. Petrópolis RJ: Vozes, 2013. . O Ser e o Nada. Petrópolis RJ: Vozes, 1997.

SAVIANI, Dermeval. As concepcões pedagógicas na bistória da educação brasileira. Texto elaborado no âmbito do projeto de pesquisa "O espaço acadêmico da pedagogia no Brasil", financiado pelo $\mathrm{CNPq}$, para o "projeto 20 anos do Histedbr”. Campinas, 25 de agosto de 2005.

SOUZA, Ilcéia $\mathrm{H}$. $\mathrm{O}$ en $e$ as relações. Série Psicologia Existencialista. Florianópolis: Edições Nuca, 1987.

TEDESCO, Juan Carlos. Educar em la Sociedad del Conocimiento. Buenos Aires: Fondo de Cultura Economica, 2009. 